\title{
A minha família existe? Deliberação e conversação política na internet
}

DOES MY FAMILY EXIST? DELIBERATION AND POLITICAL CONVERSATION IN INTERNET

\section{Danila Gentil Rodriguez Cal}

Doutora em Comunicação Social pela Universidade Federal de Minas Gerais (UFMG). Docente do Programa de Pós-Graduação em Comunicação, Cultura e Amazônia da Universidade Federal do Pará (UFPA). Líder do Grupo de Pesquisa Comunicação Política e Amazônia - Compoa (UFPA/CNPq).

E-mail: danilagentilcal@gmail.com

\section{Elias Santos Serejo}

Mestrando do Programa de Pós-Graduação em Comunicação Linguagens e Cultura da Universidade da Amazônia (Unama). Integrante do Grupo de Pesquisa Compoa (UFPA/CNPq). E-mail: eliassantos1001@gmail.com

Recebido em 31 de janeiro de 2017. Aprovado em 17 de abril de 2017.

\section{Resumo}

A definição contemporânea de família tem suscitado questionamentos sociais, políticos, simbólicos e religiosos. Neste artigo, analisamos a repercussão da campanha audiovisual realizada pelo dicionário brasileiro Houaiss que convocou a sociedade a enviar sugestões de novos conceitos para o verbete "família". O vídeo, publicado no YouTube, gerou comentários que revelam posicionamentos divergentes sobre a pauta dos direitos das famílias homoafetivas. Investigamos as trocas comunicacionais na perspectiva das conversações civis on-line e analisamos os argumentos apresentados nos comentários. Os resultados apontam, por um lado, para discursos hegemônicos centrados em ódio e desrespeito e, por outro, para a utilização do amor e do direito à diversidade como cerne dos comentários.

Palavras-chave: Família. Homossexualidade. YouTube. 


\section{Abstract}

The contemporary definition of the family has raised social, political, symbolic and religious questions. In this article, we analyze the repercussion of the audiovisual campaign carried out by the Brazilian dictionary Houaiss that called the society to send suggestions of new concepts for the entry "family". The video, published on YouTube, has generated comments that reveal divergent positions on the rights of homoaffective families. We investigate communication exchanges from the perspective of online civil conversations and analyze the arguments presented in the comments. The results point, on the one hand, to hegemonic discourses centered on hatred and disrespect, and on the other, on the use of love and the right to diversity as the core of the comments.

Keywords: Family. Homossexuality. YouTube.

\section{Introdução}

Em outubro de 2015, uma comissão especial da Câmara Federal apresentou parecer favorável à aprovação do projeto de lei que define como família apenas o núcleo formado por um homem e uma mulher e seus descendentes. Conhecido como Estatuto da Família, o texto foi rechaçado por movimentos sociais que defendem os direitos de lésbicas, gays, bissexuais, travestis e transexuais (LGBT), por entenderem que, se aprovado e sancionado, estará negando à união homoafetiva importantes direitos, como herança, adoção e inclusão de parceiros do mesmo sexo em planos de saúde e/ou previdência social, entre outros. A tramitação na comissão especial se deu em caráter terminativo, ou seja, seguirá direto para apreciação do Senado Federal, sem precisar passar pela votação no plenário da Câmara.

Com a aprovação, protestos eclodiram por todo o país proporcionando visibilidade midiática a uma das principais pautas contemporâneas dos grupos LGBT, que reivindicam o direito de terem seus núcleos afetivos reconhecidos como famílias. A discussão sobre esse assunto ocorreu também em sites de redes sociais e outros ambientes da internet.

Nesse contexto, o dicionário Houaiss, em parceria com a agência de publicidade NBS e o governo municipal do Rio de Janeiro, realizou uma campanha intitulada \#TodasAsFamílias, que convidava a sociedade brasileira a enviar conceituações próprias sobre o que é uma família. De acordo com as sugestões, o corpo técnico do dicionário iria reescrever o conceito de família na edição mais recente do dicionário, o que de fato ocorreu. Para mobilizar a 
sociedade, foram produzidos vídeos com depoimentos e imagens cotidianas de famílias dos mais diferentes formatos e modelos. O material foi postado na rede social on-line YouTube.

Investigamos, neste artigo, o processo de discussão pública on-line sobre família a partir da campanha em torno do significado do verbete família. Com esse objetivo, analisamos as falas de interlocutores no ambiente on-line, observando especialmente os argumentos a favor e contra a família homoafetiva, além de categorizar as falas e apontar potenciais deliberativos nas trocas argumentativas.

Como objeto empírico, nossa abordagem utilizará as conversações on-line realizadas especificamente sobre o vídeo principal da campanha, que possuía 57 comentários até o dia 15 de junho de 2016. O vídeo, com duração de 2 minutos e 54 segundos, foi publicado no canal do YouTube "Todas as famílias" (O QUE..., 2016) e possui o título "O que é família? \#TodasAsFamílias". Nossa análise se foca nas perspectivas e nos argumentos defendidos pelos interlocutores que comentaram o vídeo. Busca-se refletir sobreas trocas argumentativas à luz da teoria deliberativa e do agir comunicativo (HABERMAS, 1984).

Como ambiente de trocas argumentativas, a internet tem se apresentado como objeto de inúmeros estudos que se debruçam sobre as possibilidades de formação de uma esfera pública on-line e/ou ambiente de conversação civil e ampliam diálogos sobre temas concernentes à sociedade (MENDONÇA; PEREIRA, 2011; MARQUES, 2006). Há autores, inclusive, que apontam para uma revitalização da democracia com o advento das redes sociais que permitem participação ampla, livre e massiva de diferentes indivíduos em debates que lhes causam algum tipo de interesse (MENDONÇA; PEREIRA, 2011). Vale ressaltar a extensa literatura publicada pelos autores deliberacionistas brasileiros (MENDONÇA; PEREIRA, 2011; MARQUES, 2006; MAIA; REZENDE, 2015), que se dedicam a refletir sobre o papel da internet no fortalecimento da democracia brasileira na perspectiva de contribuir com os desdobramentos das teorias fundadas pelo filósofo e sociólogo alemão Jürgen Habermas, a saber a principal: a democracia deliberativa.

Mendonça e Pereira (2011) afirmam que na internet é possível aproximar representantes da sociedade, fortalecer a cultura cívica, fundar outras modalidades de participação, além de fomentar o debate público por meio da produção de informações disponíveis aos diferentes públicos. De modo complementar, Maia et al (2015) defendem que conversações contemporâneas entre cidadãos são realizadas de modo complexo e com a usabilidade das redes sociais foi alterada dramaticamente a infraestrutura da conectividade social, o que tornou o ambiente político mais poroso, capaz de ouvir vozes antes esquecidas. 


\section{Famílias no Brasil contemporâneo: a campanha para mudança conceitual da palavra família no Houaiss}

O motivo da mudança do significado da palavra família no Houaiss foi ampliar o significado da palavra, de modo que contemple as mais diversas formas de família existentes. De acordo com matéria publicada no site G1, o conceito de família era: "família 1. grupo de pessoas vivendo sob o mesmo teto (esp. o pai, a mãe e os filhos)" (CAMPANHA..., 2016). Com a reformulação, o conceito passou a ser: "família 1. núcleo social de pessoas unidas por laços afetivos, que geralmente compartilham o mesmo espaço e mantém entre si uma relação solidária" (Ibid., 2016).

A mudança contou com a participação da sociedade brasileira, que enviou as próprias concepções de família para contribuir com a reformulação. A campanha \#TodasAsFamílias foi realizada pela agência de publicidade e propaganda NBS, em parceria com o dicionário Houaiss e a Coordenadoria Especial da Diversidade Sexual do Rio de Janeiro, contando também com o apoio da Associação Brasileira de Famílias Homoafetivas (Abrafh). O grupo criou um site e um canal na rede social YouTube, nos quais disponibilizou vídeos com depoimentos de famílias plurais. Neste trabalho, tratamos especificamente do vídeo principal da campanha, que apresenta um compilado dos demais registros publicados de formas curtas e individuais no canal da campanha no YouTube. Com duração de 2 minutos e 54 segundos, o vídeo convida a sociedade a enviar sua definição de família. Ele foi publicado no dia 11 de abril de 2016 e, até o dia 15 de junho de 2016, já havia sido visto por 13.117 pessoas e suscitado 57 comentários.

Segundo Passos (2005), as múltiplas modalidades de famílias que ganharam visibilidade no Brasil contemporâneo expressam as transformações profundas ocorridas no cerne da relação família-indivíduo-sociedade. Nesse debate, a família homoafetiva - núcleos familiares em que o casal é formado por pessoas do mesmo sexo - possui nuances próprias que se apresentam revolucionárias por superar alguns princípios considerados fundamentais para a sociedade patriarcal na constituição do grupo familiar: a procriação e a diferenciação sexual (Ibid.).

Nesse contexto, o modelo nuclear de família (homem e mulher) ainda tende a ser visto como imutável, inequívoco e natural, negando, assim, a família como instituição social e historicamente construída. Essa concepção, além de ser altamente excludente, privilegia um único modelo de família frente a múltiplos arranjos que vivenciamos apenas no Brasil. A partir disso, portanto, o surgimento de conflitos, estigmas e preconceitos direcionados às famílias que destoam do padrão imposto, sobretudo as famílias formadas por casais do mesmo sexo (SANTOS; SCORSOLINI-COMIN; SANTOS, 2013).

"Embora a homossexualidade tenha uma longa história em vários cenários culturais, nos quais, muitas vezes, as pessoas tinham filhos, só muito recentemente a 
homoparentalidade vem se tornando mais visível no contexto social brasileiro" (PASSOS, 2005, p. 32). A visibilidade dessa modalidade familiar muito se deve às discussões travadas na esfera pública nos âmbitos de política, mídia e entretenimento - novelas ousam e inserem em suas tramas casais homossexuais ocupando a posição de provedores e sendo descritos na narrativa como alicerce de famílias estruturadas. A campanha do dicionário Houaiss buscou estimular o olhar para essa diversidade de formações familiares e provocar reflexão social por meio de nova definição do vocábulo.

\section{Deliberação e conversação civil na internet: algumas perspectivas}

Quando nos preocupamos em conhecer, analisar e avaliar os discursos proferidos durante trocas comunicativas públicas sobre os direitos de grupos ou sujeitos subalternizados, consideramos pertinente recorrer às discussões sobre estudos de deliberação e conversação civil na internet. Isso porque as redes sociais on-line ocupam espaço significativo nas pesquisas contemporâneas realizadas no âmbito da democracia deliberativa (MAIA et al., 2015).

Marques (2006) analisa teoricamente a democracia na interface com novas tecnologias digitais e apresenta discussões em torno dos conceitos de esfera pública, deliberação, esfera pública virtual e conversação civil on-line. O levantamento do estado da arte do conceito de "esfera pública" nos interessa aqui porque apresenta as possibilidades de estabelecimento de versão virtual desse ambiente/fluxo discursivo (MARQUES, 2006). O autor sustenta a ideia de que em ambiente virtual a esfera pública atuaria como ambiente de conversação civil. Nessa perspectiva, as discussões abertas realizadas na internet "atuam de modo mais eficaz como espaço destinado à formação complementar de opiniões do que como um espaço decisório por excelência" (MARQUES, 2006, p. 164).

A comunicação digital, explica Marques (2006), supera as barreiras do espaço tendo em vista que a internet destitui fronteiras e permite a interação entre indivíduos localizados em diferentes contextos geográficos. Portanto, o direito de uso da palavra, livre na internet, estabeleceria o que ele denomina de espaço argumentativo digital. O computador, nessa perspectiva, seria um meio de comunicação diferenciado em termos políticos (Ibid.).

Para sustentar essas afirmações, Marques (2006) dialoga com diferentes autores que apontam aspectos que tornam a internet um espaço revigorante da esfera pública argumentativa por dois motivos: por ser um espaço em que vozes marginais têm a oportunidade de se expressarem sem que o poder estatal realize algum tipo de censura e/ou coerção e também por garantir reciprocidade. Essas vozes marginais foram percebidas 
nos discursos proferidos nos comentários do vídeo, em que tanto comentários em prol da mudança quanto naqueles contra ela tiveram o mesmo espaço e direito à réplica e tréplica quantas vezes foi necessário.

Nas sociedades democráticas contemporâneas, discute Marques (2006), as novas tecnologias tornam instável o debate conceitual sobre a esfera pública enquanto categoria fundamental para compreensão da relação entre Estado e esfera civil. Para Marques (2006), trata-se de uma rede de comunicação pública nem sempre institucionalizada, dotada de possibilidades comunicativas que podem ser desenvolvidas em diversas arenas de debates, por vezes a internet suscita o que o autor identifica como "formação espontânea de opiniões".

Analisar a mobilização no YouTube pode nos ajudar a compreender as dinâmicas sociais contemporâneas, já que perpassa por protestos e ativismos políticos, assim como discussões ordinárias. Diante disso, faz-se necessário compreender como e se a plataforma contribui para levar questões à "esfera de visibilidade pública, o modo como altera tradicionais demarcações entre o público e o privado e, ainda, sua capacidade de alimentar discussões e conversações públicas" (OLIVEIRA; SARMENTO; MENDONÇA, 2014, p. 55).

Segundo Oliveira, Sarmento e Mendonça (2014), a divulgação massiva em redes como o YouTube, em que os conteúdos são produzidos por diversas fontes, pode tornar os cidadãos ainda mais informados e podendo participar de esferas de debates que dificilmente comporiam antes. A conversação realizada em espaços virtuais como o YouTube tornaria a esfera civil mais povoada, tendo em vista o empobrecimento devido à ausência de debate.

"Ainda que não se possa dizer que um conjunto de expressões soltas constitua uma deliberação, é importante observar como conversas aparentemente informais são essenciais à vivacidade política da esfera pública" (Ibid., p. 57). Contudo, destacamos que há desigualdades relevantes que estão expressas sobretudo na relação de uso da rede, já que nem todos possuem recursos e/ou capacidades para utilizar as tecnologias, portanto as trocas argumentativas na internet precisam ser olhadas com cautela. O potencial deliberativo no âmbito das redes estaria, portanto, relacionado à "capilaridade e projeção social que tais plataformas têm possibilitado a discussões sobre temas de interesse público" (Ibid., p. 58).

\section{Procedimentos metodológicos}

As conversações informais desencadeadas nos comentários do vídeo tornaram públicas - no sentido de ser acessível e aberto para todos com acesso à internet - as 
múltiplas visões que os participantes das trocas comunicacionais possuem sobre a família homoparental. O vídeo "Todas as famílias" inicia apresentando a então definição do conceito de família no dicionário. Em tom documental, resgata as relações familiares formadas por diversos núcleos, valendo ressaltar que as famílias que integram o vídeo são reais.

$\mathrm{O}$ vídeo também aborda por meio de referência a matérias jornalísticas a aprovação, na comissão especial da Câmara, do Estatuto da Família. O vídeo explora em pouco mais de dois minutos as pluralidades de famílias que existem no Brasil contemporâneo na tentativa de sensibilizar o espectador.

Apesar de o vídeo retratar famílias dos mais diversos modelos, os comentários focaram apenas na família formada por casais homoafetivos. Analisamos os 57 comentários postados no YouTube - tanto comentários propriamente quanto respostas a eles - a partir dos seguintes aspectos: quais as fontes de autoridade de quem comenta; a identidade de gênero que se apresenta no perfil (embora a rede social permita comentários anônimos ou com nomes falsos); o núcleo central que sustenta os posicionamentos utilizados na troca comunicativa; o conteúdo do próprio comentário; e, por fim, observações gerais sobre a relação entre comentários e conteúdo do vídeo.

A partir dos dados sistematizados, iniciamos a discussão sobre as trocas comunicacionais realizadas no vídeo. É relevante citar que nossa análise se deteve muito a trocas e conversações do que necessariamente ao potencial deliberativo do ambiente analisado. Das 57 publicações sobre vídeo, 21 eram comentários e 36 eram respostas aos comentários; 13 comentários foram feitos por homens, os quais também foram responsáveis por 23 respostas a comentários, e as mulheres somaram 8 comentários, respondendo a comentários 13 vezes.

A partir de metodologia proposta por Maia et al. (2015), trabalhamos com cinco categorias que abordam as fontes de autoridade com objetivo de identificarmos não apenas os argumentos levantados pelos interlocutores, mas também a partir de qual fonte ele se sustenta (Tabela 1). De acordo com Maia et al. (2015), a fonte de autoridade indica o lugar de fala e com que propriedade o falante apresenta os argumentos e pode ser classificada em: especialista, referindo-se ao argumento que apresenta pontos de vista de alguém que compreende o assunto; tradição, que diz respeito aos argumentos que apontam para história da sociedade, práticas que fazem parte da sociedade e normatividade; reivindica representação da maioria das pessoas, referindo-se ao status quo, ao que está imposto, isto é, a normatividade; experiência pessoal; e, por fim, papel legal/poder de polícia, recorrendo ao poder de fiscalização (MAIA et al., 2005). Em relação a esta última fonte, não encontramos ocorrências no material investigado. 
Tabela 1. Fontes de autoridades localizadas

\begin{tabular}{ccccccc} 
& & & \multicolumn{5}{c}{ Gênero } \\
\cline { 4 - 7 } Fontes autoridade & Ocorrências & \% de ocorrências & M & M\% & F & F\% \\
Especialista & 8 & 14,0 & 7 & 19,4 & 1 & 4,8 \\
\hline Tradição & 11 & 19,3 & 7 & 19,4 & 4 & 19,0 \\
\hline $\begin{array}{c}\text { Reivindica representação da } \\
\text { maioria das pessoas }\end{array}$ & 5 & 8,8 & 4 & 11,1 & 1 & 4,8 \\
\hline Experiência pessoal & 17 & 29,8 & 9 & 25,0 & 8 & 38,1 \\
\hline Sem fontes de autoridade & 16 & 28,1 & 9 & 25,0 & 7 & 33,3 \\
\hline Total & $\mathbf{5 7}$ & $\mathbf{1 0 0 , 0}$ & $\mathbf{3 6}$ & $\mathbf{1 0 0 , 0}$ & $\mathbf{2 1}$ & $\mathbf{1 0 0}$ \\
\hline
\end{tabular}

Elencamos ainda dezessete ideias norteadoras que apareceram de modo recorrente nos argumentos apresentados (Tabela 2). Essas categorias foram criadas para que fornecessem indicadores sobre os conteúdos publicados, tornando mais claras as perspectivas de cada interlocutor e nos ajudando a olhar para o cerne da questão, ou seja, de que forma se posicionam e interagem nas trocas comunicativas. Como exemplo, temos: questionamentos acerca da razão da campanha, questões de cunho religioso e papel de gênero numa relação família de núcleo heterossexual. Alguns comentários apresentaram mais de uma ideia norteadora.

Tabela 2. Ocorrências das ideias norteadoras identificadas

\begin{tabular}{|c|c|c|}
\hline Ideia norteadora do argumento & $\mathbf{N}$ & $\%$ \\
\hline $\begin{array}{l}\text { Ênfase no amor como fundamento para formação de famílias e não a forma como o núcleo } \\
\text { familiar é formado }\end{array}$ & 6 & 8,0 \\
\hline Consideração sobre a normalidade das relações homoafetivas & 3 & 4,0 \\
\hline Conceituação de família engessada na procriação e no núcleo formado por casais heterossexuais & 15 & 20 \\
\hline Preocupação com o futuro das crianças criadas em lares homoafetivos & 1 & 1,3 \\
\hline $\begin{array}{l}\text { Conceituação da homossexualidade como algo anormal, pois filhos gerados em lares } \\
\text { homoafetivos podem virar homossexuais }\end{array}$ & 2 & 2,6 \\
\hline Ênfase na crítica à mudança de conceituação da palavra família pelo dicionário & 4 & 5,3 \\
\hline Ênfase na religião como ponto de partida para posicionamento & 8 & 10,6 \\
\hline Preocupação com o papel de gênero na criação dos filhos & 2 & 2,6 \\
\hline
\end{tabular}


Tabela 2. Continuação

\begin{tabular}{|c|c|c|}
\hline Preocupação com as transformações sociais que estão ocorrendo em vários aspectos sociais & 2 & 2,6 \\
\hline $\begin{array}{l}\text { Convocação do interlocutor a conhecer mais sobre o tema da campanha e apresentação de links } \\
\text { com informações }\end{array}$ & 2 & 2,6 \\
\hline Interpelação ao pedir argumentos válidos & 2 & 2,6 \\
\hline Refutação à ideia da procriação, apresentando argumentos que invalidam essa visão & 2 & 2,6 \\
\hline Insulto & 4 & 5,3 \\
\hline Não houve argumento & 16 & 21,3 \\
\hline Total & 75 & 100 \\
\hline
\end{tabular}

Fonte: Dados da pesquisa.

Seguindo uma trajetória de análise que dialoga com o trabalho realizado por Marques e Martino (2012), elaboramos um quadro analítico com três aspectos gerais nos quais trocas comunicacionais e argumentos utilizados pelos usuários da rede podem ser inseridos. A reflexão a partir dessa categorização foi realizada tendo em vista âmbito do conteúdo dos argumentos, lugar de fala dos interlocutores e contribuição para reflexão sobre o tema proposto.

Faz-se necessário, portanto, apresentar o enquadramento exposto no Quadro 1 e utilizado para analisar os comentários. Partiu-se dos aspectos gerais que estão inseridos na coluna "exposições de posicionamento", que dizem respeito ao que falam os que comentam, que informações utilizam para comentar e o conteúdo desses posicionamentos. Após a elaboração do eixo com os aspectos gerais, desenvolvemos os "princípios normativos da argumentação", ou seja, aspectos da forma com a qual se posicionam, estando inclusa a subjetividade das conversações com nuances próprias da linguagem utilizada em ambientes on-line. Ao nos debruçarmos sobre os comentários, perguntamos o que devíamos observar e, após leitura dos argumentos apresentados e sob lentes das conversações civis on-line, chegamos ao que pode ser observado no Quadro 1: 
Quadro 1. Modelo analítico da pesquisa

\begin{tabular}{|c|c|c|}
\hline $\begin{array}{l}\text { Exposiçōes de } \\
\text { posicionamento }\end{array}$ & $\begin{array}{l}\text { Princípios normativos da } \\
\text { argumentação }\end{array}$ & O que observar? \\
\hline $\begin{array}{l}\text { Compreensão da causa } \\
\text { como aspecto da sociedade } \\
\text { contemporânea a ser } \\
\text { considerado por todos. }\end{array}$ & $\begin{array}{l}\text { Discussão crítico-racional com } \\
\text { ênfase na tomada de decisão sobre } \\
\text { ser contra ou a favor da família } \\
\text { homoparental. }\end{array}$ & $\begin{array}{l}\text { Busca pela exposição de ideias racionais } \\
\text { embasadas por informações amplamente } \\
\text { divulgadas e disponíveis; afetividade entre } \\
\text { pessoas do mesmo sexo vista com normalidade; } \\
\text { realidade social do preconceito no Brasil } \\
\text { contemporâneo. }\end{array}$ \\
\hline $\begin{array}{l}\text { Compreensão da causa no } \\
\text { âmbito da religião e do } \\
\text { determinismo biológico. }\end{array}$ & $\begin{array}{c}\text { Reflexividade sobre a vida do } \\
\text { outro a partir de convicções } \\
\text { próprias. }\end{array}$ & $\begin{array}{l}\text { Discursos inflamados pela imposição de dogmas } \\
\text { pessoais; valores que dizem respeito à tradição } \\
\text { familiar patriarcal existente no Brasil; papel do } \\
\text { homem e da mulher na educação de uma criança } \\
\text { e na condução de uma família. }\end{array}$ \\
\hline $\begin{array}{l}\text { Críticas ao formato } \\
\text { "ideológico" da campanha, } \\
\text { insultos e incitação ao } \\
\text { ódio. }\end{array}$ & $\begin{array}{l}\text { Tentativa de anulação do } \\
\text { interlocutor por meio da imposição } \\
\text { de conceitos e/ou argumentos que } \\
\text { reiteram o status quo }\end{array}$ & $\begin{array}{l}\text { Se por um lado pouco dialogam com a proposta } \\
\text { da campanha, por outro há severas críticas ao } \\
\text { avanço das pautas da diversidade na sociedade, } \\
\text { elencadas como "ideológicas"; troca de } \\
\text { insultos; reiteração da dicotomia certo e errado } \\
\text { observando que a vivência de quem comenta é } \\
\text { sempre a certa. }\end{array}$ \\
\hline
\end{tabular}

Fonte: Elaboração dos autores a partir do trabalho de Marques e Martino (2012).

\section{Compreensão da causa como um aspecto da sociedade contemporânea a ser considerado por todos}

As exposições argumentativas de posicionamentos favoráveis à família homoparental foram as primeiras a surgir na lista de comentários do vídeo. Os perfis que comentaram procuraram expor satisfação e contentamento com a campanha, apontando certa sensação de representatividade nas famílias que aparecem no vídeo. Reunimos as ideias norteadoras das categorias citadas na Tabela 1 levando em consideração as diretrizes escolhidas para a análise nos três eixos da Tabela 2. Percebemos que os comentários buscam, sobretudo, a exposição de ideias racionais embasadas por informações amplamente divulgadas e disponíveis.

As ideias norteadoras que se destacaram nesse eixo foram: "ênfase no amor como fundamento para formação de famílias e não a forma como o núcleo familiar é formado"; "consideração sobre a normalidade das relações homoafetivas"; "consideração sobre o lugar de fala do interlocutor"; "preocupação com a natureza das relações afetivas para além do sexo"; "preocupação com as transformações sociais que estão 
ocorrendo em vários aspectos sociais"; "cconvocação do interlocutor a conhecer mais sobre o tema da campanha e apresentação de links com informações"; "interpelação ao pedir argumentos válidos"; "refutação à ideia da procriação, apresentando argumentos que invalidam essa visão".

Que projeto maravilhoso! Eu, como mulher homossexual vivendo um relacionamento de quase 5 anos, me senti MUITO feliz ao assistir esses vídeos. É confortante o sentimento de ver pessoas como eu levando uma vida "normal" e feliz com seus filhos e companheiros (as). Obrigada, de verdade! Saibam que além de passar uma mensagem linda vocês estimulam várias pessoas a irem atrás dos seus sonhos. Eu quero muito construir uma família com minha namorada, e ver esse vídeo com tanta gente feliz só me motivou a correr atrás disso. (O QUE..., 2016, Comentarista 1)

Porque, pra mim, família é o lugar onde a gente recebe tanto amor a ponto de sentir que nada nem ninguém no mundo pode nos fazer mal. \#TODASASFAMILIAS. (Ibid., Comentarista 2)

Bom O erro não está no dicionário, mas na comissão especial. O que a campanha propõe é o apoio às milhões de famílias que não são contempladas pelo conceito ultrapassado e pejorativo que o Estatuto Preconceituoso propôs. (Ibid., Comentarista 3)

Os comentários acima são exemplos da ideia norteadora "ênfase no amor como fundamento para formação de famílias e não a forma como o núcleo familiar é formado", em que reunimos comentários que aprovaram o projeto como iniciativa da sociedade para contribuir com o debate sobre as "novas" famílias. Esses usuários apoiam o movimento e apresentam argumentos que consolidam seus posicionamentos. Foram encontradas seis ocorrências nessa modalidade, sendo três comentários e três respostas a comentários. Sobre a fonte de autoridade, encontramos nesse grupo unicamente a "experiência pessoal".

Outro exemplo que consideramos importante discutir é a ideia norteadora "preocupação com as transformações sociais que estão ocorrendo em vários aspectos sociais". Percebemos nessa categoria certo anseio dos participantes em validar seus discursos por meio da apresentação da luta histórica das populações que transgridem a noção de normalidade imposta pela sociedade patriarcal ocidental. Partindo dessa premissa, verificamos que os dois comentários agregados foram feitos por homens, cujas fontes de autoridades foram a experiência pessoal, que apontam inquietude com os rumos que a conversação tomou. 
O dicionário Oxford adicionou ano passado o pronome de tratamento $\mathrm{Mx}$, para quem não se identifica com a ideia de gênero binário. Aceita, amigo. A sociedade muda, evolui e adapta-se. Apenas. (Ibid., Comentarista 5)

Ser contra a escravidão, ser a favor dos direitos da mulher... exemplos do que já foi considerado "discurso político". Você escolhe a sua posição na História. Espero que reveja os seus conceitos, desenvolva respeito pela dignidade humana de quem é diferente, e esteja do lado de quem não discrimina. A escolha é sua. Coloque-se no lugar do outro. (Ibid., Comentarista 6)

Ao apresentar seus argumentos, eles enfatizam as transformações sociais ocorridas nos últimos anos no Brasil e reiteram a necessidade de ter empatia com o outro.

\section{Compreensão da causa no âmbito da religião e do determinismo biológico}

Em diálogos travados no ambiente virtual sobre homossexualidade, sobretudo quando o tema é a formação de famílias, verificamos com frequência a presença de argumentos embasados em fundamentalismos religiosos preocupados muito mais com dogmas que o proponente da comunicação professa do que com avaliar a conjuntura nacional em relação ao avanço dos direitos humanos. Essa situação também foi encontrada nesta pesquisa. Reunimos no mesmo grupo os argumentos embasados no âmbito da religião e o determinismo biológico por considerar que os dois aspectos convergem na mesma ação: acreditar que família está ligada apenas ao ato da procriação. Foram recorrentes nessa perspectiva as seguintes ideias norteadoras: "conceituação de família engessada na procriação e no núcleo formado por casais heterossexuais"; "preocupação com o futuro das crianças criadas em lares homoafetivos"; "ênfase na religião como ponto de partida para posicionamento"; e, por fim, "preocupação com o papel de gênero na criação dos filhos".

Os comentaristas do vídeo que enquadramos na ideia norteadora "conceituação de família engessado na procriação e no núcleo formado por casais heterossexuais" acreditam na instituição família como um núcleo fechado sem margens para emergência de outros modelos e para isso afirmam que, por ser uma criação divina, deve ser preservada. $\mathrm{O}$ argumento da preservação da família diz respeito ao fato de homossexuais não poderem procriar entre si. Esse discurso renega as tecnologias de reprodução assistida e outras formas de gerar filhos. Localizamos quinze comentários nessa categoria, dos quais dez foram feitos por homens e cinco por mulheres. As fontes de autoridades variam entre: "especialista"; "tradição"; "reivindicação de representação da maioria das pessoas"; e 
"experiência pessoal". O comentário a seguir é um exemplo da fonte de autoridade "tradição", tendo em vista os argumentos utilizados que enaltecem as relações culturais e religiosas historicamente impostas à sociedade ocidental:

o mais importante e que a familia e tao importante para o mundo, por isso que foi Deus quem criou a familia, que nao podemos reduzi-la por so palavras movidas emocoes humanas. Por exemplo, quantos divorcios e separacoes acontecem por essa razao: "sentimento humano"? ela e muito mais e vai ao mais profundo do ser humano, alem de sentimentos, isso e muito serio. vamos parar de brincar com essa realidade tao linda mas tambem tao seria. tao estragando com tantos exemplos, palavras bonitas mas... niguem chega ao nucleo, a raiz de que o que e familia no seu ser como foi criada. Que Deus nos ajude. (Ibid., Comentarista 7)

A ideia norteadora "preocupação com o futuro das crianças criadas em lares homoafetivos" causou tensões nas trocas comunicativas por apontar a possibilidade de geração de distúrbios emocionais e/ou psíquicos em uma criança criada em um lar homoafetivo. Esse tema foi utilizado por um comentarista do vídeo para justificar o argumento a partir da fonte de autoridade "tradição".

Casal é Homem e Mulher, Família é Pai, Mãe e Filhos, ou Pai e filhos, ou Mãe e filhos. Qualquer família onde há filhos sendo criados por 2 pais ou 2 mães casados ou com um relacionamento afetivo sob o mesmo teto é coisa de uma sociedade contemporânea corrompida pela luxúria, egoísmo e coisas do tipo. Uma família nesses moldes é uma família egoísta, onde não há a mínima preocupação com futuros problemas psicológicos que esses filhos possam vir a desenvolver. Mas sempre dão um jeitinho, sempre reina a bela desculpa do que importa é dar felicidade, carinho, amor e tudo para a criança, como se ela fosse criança para sempre. E o futuro da criança? Ahh, isso ela que se lixe, goste ou não, terá que se acostumar com os pais modernos, e a explicar para a sociedade que ela veio de uma cegonha e possui 2 pais ou 2 mães. E caso essa criança cresça e comece a estranhar a ideia da família moderna, terá que se acostumar ou cai fora de casa, ou virar homossexual também e perpetuar a ideia novamente. Todo(a) homossexual se diz feliz, mas parece que esquecem que veio de um coito entre um homem e uma mulher, que tal perpetuar essa felicidade? não seria uma boa ideia espalhar a felicidade da procriação? Sim essa mesma felicidade que você tem por existir. Refletem aí. (Ibid., Comentarista 8)

Qual é o futuro de uma criança criada por dois pais e uma mãe? A pergunta norteia os debates sobre as famílias homoparentais e está no cerne da discussão do estatuto da família, por exemplo. 


\section{Críticas ao formato "ideológico" da campanha, insultos e incitação ao ódio}

Observamos que a campanha \#TodasAsFamílias incomodou alguns comentaristas do vídeo por, segundo eles, acompanhar uma ideologia que estaria sendo imposta à sociedade, a qual estaria obrigando as pessoas ditas "normais" a serem obrigadas a conviver com as diversidades. Como ideologia, essa imposição estaria adentrando os mais diversos segmentos da sociedade na tentativa de proporcionar a desordem na família tradicional brasileira. Além do fator ideológico, comentaristas das categorias reunidas nesse eixo apresentaram insulto e incitação ao ódio. Seguem as ideias norteadoras enquadrados nesse eixo: "conceituação da homossexualidade como algo anormal, pois filhos gerados em lares homoafetivos podem virar homossexuais"; "ênfase na crítica à mudança de conceituação da palavra família pelo dicionário"; "crítica à campanha por acreditar ser doutrinamento ideológico"; "qquestionamento aos aspectos 'ideológicos' da campanha"; e "insulto".

Primeiramente, Dicionário nenhum é autoridade moral ou científica para definir por si o conceito de família, pouca interessa se é Oxford, conceitos oriundos da ideologia de gênero pertencem a discussão da sociedade, que por sinal ainda mantem(goste ou não)a contrariedade a respeito do tema, e sendo portanto material subjetivo, não convem a um livro técnico versar sobre isso mas sobre objetividades. Marxismo cultural e modismo não fazem parte de conteúdo intelectual de respeito. A sociedade muda, mas valores fundamentais permanecem, aceite. (Ibid., Comentarista 9)

A campanha para envio de sugestões de conceituações do termo "família" no Houaiss soou como oportunista para alguns comentaristas do vídeo, tendo em vista se tratar de um assunto que está na agenda pública de discussões e para eles estaria sendo utilizada como imposição ideológica, tratando-se, assim, de uma avaliação que busca justificar preconceitos. Os comentários agrupados nessa categoria apontam para a falta de argumentação baseada em conhecimento científico, social e de empatia com os direitos humanos. Ao defender que uma família formada por homossexuais não é uma família, esses comentaristas não dialogam com seus pares apresentando questões válidas, apenas achismos, preconceitos e conservadorismo.

Nessa categoria, foram registrados quatro comentários, dois feitos por homens e outros dois por uma mesma mulher, as fontes de autoridades encontradas foram "reivindicação de representação da maioria das pessoas" e "especialista".

$146 \frac{\text { Comunicação \& Inovação, PPGCOM/USCS }}{\text { v. 18, n. } 37 \text { (133-148) maio-ago } 2017}$ 


\section{Considerações finais}

O objetivo deste artigo era analisar o processo de discussão pública on-line sobre família a partir da campanha "O que é família? \#TodasAsFamílias". Para tanto, recorremos à literatura sobre internet e política, especialmente a voltada para análise de debates públicos on-line. Como viés metodológico, aproximamo-noss de deliberação on-line, processos de conversações civis e estudo de caso.

Os comentários analisados apresentaram diversas temáticas para defender pontos de vistas a favor e contra a família formada por um núcleo homoafetivo. Se por um lado os comentários no vídeo apresentam pouca ou nenhuma troca argumentativa com fins deliberativos, por outro representam um recorte social dos pontos de vistas pessoais que ganham eco on-line. Essas conversações civis elucidaram eixos centrais comuns aos discursos e argumentos sobre a temática, como a questão religiosa e o condicionamento biológico para procriação. Os argumentos encontrados na categoria "críticas ao formato 'ideológico' da campanha, insultos e incitação ao ódio" relativizam a luta das pessoas LGBT pelo reconhecimento de seus núcleos familiares ao afirmar que valores fundamentais (família heterossexual) não podem mudar.

Debruçar-se sobre esses fenômenos nos ajuda a compreender quais elementos compõem os argumentos presentes nesse debate e proporciona reflexão sobre quais forças hegemônicas estão atuando no imaginário social. A quem interessa impedir que dois homens adotem uma criança? Afinal, duas mulheres não podem ser mães dos filhos de apenas uma delas? Por quê?

A internet é palco para diversos tipos de argumentações, contrárias ou a favor de temas variados, sobretudo nas redes sociais. Para defender pontos de vistas, interlocutores utilizam argumentos que nem sempre consideram a construção coletiva e o aperfeiçoamento cidadão. Mas quem realmente está interessado no diálogo? Ou na troca argumentativa direcionada para mudança e transformação? Este artigo contribui ao buscar os elementos centrais em falas proferidas no ambiente virtual, categorizá-los e os organizar a partir de eixos que nos façam refletir sobre o que querem aqueles que comentam em vídeos do YouTube, o porquê de comentarem e os lugares de fala e fontes de autoridade.

Ao elucidar esse processo, este texto se propõe a ser um ensaio sobre os argumentos utilizados na web para debater questões voltadas para a população LGBT, com ênfase na questão das formações de famílias. Apesar de os argumentos apresentados nos comentários analisados se distanciarem dos ideais deliberativos, por outro lado fortalecem as conversações civis ao apresentar diferentes pontos de vista, como também contribuem para estimular o processo de debate sobre o assunto. 


\section{Referências}

BURGESS, J.; GREEN, J. Youtube e a revolução digital: como o maior fenômeno da cultura participativa transformou a mídia e a sociedade. São Paulo: Aleph, 2009.

CAMPANHA incentiva mudança do significado de família no dicionário. G1, São Paulo, 12 abr. 2016. Disponível em: <https://goo.gl/aAzeR4>. Acesso em: 20 maio 2016.

HABERMAS, J. The theory of communicative action. Boston: Beacon Press, 1984. v. 1.

MAIA, R. C. M.; et al. Negotiating conflict across deep divisions in face-to-face group discussions: an examination of deliberative transformative moments. In: INTERNATIONAL COMMUNICATION ASSOCIATION ANNUAL CONFERENCE, 65., 2015, Puerto Rico. Proceedings... Puerto Rico: ICA, 2015. v. 65.

MAIA, R. C. M.; MARQUES, F. P. J. A.; SAMPAIO, R. C. Participação e deliberação na internet um estudo de caso do orçamento participativo digital de Belo Horizonte: Opinião Pública, Campinas, v. 16, n. 2, p. 446-477, 2010. Disponível em: <https://goo.gl/SdnBmh>. Acesso em: 21 maio 2016.

MAIA, R. C. M.; REZENDE, T. A. S. Democracia e a ecologia complexa das redes sociais online: um estudo sobre discussões acerca do racismo e da homofobia. Intexto, Porto Alegre, n. 34, p. 492-512, 2015. Disponível em: <https://goo.gl/1t2y1z>. Acesso em: 20 maio 2016.

MARQUES, A. S.; MARTINO, L. M. S. Deliberação online e opinião pública no caso do movimento gota d'água contra a usina de belo monte. Contemporânea: comunicação e cultura, v. 10, n. 3, p. 530556, 2012. Disponível em: <https://goo.gl/EvYB4R>. Acesso em: 29 maio 2016.

MARQUES, F. P. J. A. Debates políticos na internet: a perspectiva da conversação civil. Opinião Pública, Campinas, v. 12, n. 1, p. 164-187, 2006. Disponível em: <https://goo.gl/j0F3rb>. Acesso em: 20 maio 2016.

MENDONÇA, R. F.; PEREIRA, M. A. Democracia digital e deliberação online: um estudo de caso sobre o VotenaWeb. In: CONGRESSO LATINO AMERICANO DE OPINIÃO PÚBLICA, 4., 2011, Belo Horizonte. Anais... Belo Horizonte: Wapor, 2011. Disponível em: <https://goo.gl/LblYlI>. Acesso em: 23 maio 2016.

OLIVEIRA, W. M. de; SARMENTO, R; MENDONÇA, R. F. Deliberação no Youtube? Debates em torno da questão LGBT. Revista Compolítica, Rio de Janeiro, n. 4, v. 1, 2014. Disponível em: <https:// goo.g1/DT0Ou5>. Acesso em: 27 maio 2016.

O QUE é família? \#todasasfamilias. 2'54”. Todas as Famílias, Youtube, 11 de abril de 2016. Disponível em: $<$ https://goo.gl/o2ryKz> . Acesso em: 20 maio 2016.

PASSOS, M. C. Homoparentalidade: Uma entre outras formas de ser família. Psicologia Clínica, Rio de Janeiro, v. 17, n. 2, p. 31-40, 2005. Disponível em: <https://goo.gl/DiqbHr>. Acesso em: 21 maio 2016.

SANTOS, Y. G. S.; SCORSOLINI-COMIN, F.; SANTOS, M. A. Homoparentalidade masculina: revisando a produção científica. Psicologia: Reflexão e Crítica, Porto Alegre, v. 26, n. 3, p. 572-582, 2013. Disponível em: $<$ https://goo.gl/UgAXIg $>$. Acesso em: 26 maio 2016. 